\title{
Process configuration - combining the principles of product configuration and process planning
}

\author{
K. Schierholt \\ Institute of Industrial Engineering and Management (BWI) \\ Swiss Federal Institute of Technology (ETH) Zürich \\ Zürichbergstrasse 18, CH 8028 Zürich, Switzerland \\ e-mail: schierholt@bwi.bepr.ethz.ch
}

\begin{abstract}
Product Configuration is the process of generating a product variant from a previously defined product family model and additional product specifications for this variant. The process of finding relevant operations for manufacturing this product and putting these into order is called process planning. This paper describes main characteristics of the product configuration and process planning principles and leads to the new concept of process configuration which solves the process planning task using product configuration principles.

The second section develops characteristics for two process configuration concepts, the interactive process configuration and the automation-based process configuration. For both concepts, requirements on process configuration systems are defined and ideas are presented how the systems could be designed to match the requirements. This is followed by an overview over a prototype implementation of a process configuration system in the metal working industry.
\end{abstract}

\section{Keywords}

Product configuration, process planning, computer-aided process planning (CAPP), process configuration, multiple-variant products 


\section{PROCESS CONFIGURATION AS AN ENHANCED PROCESS PLANNING CONCEPT}

Through increased market pressure on companies, the number of products that are produced specifically to customer specifications increases steadily. Such products, that are very similar in their general structure but differ in details of each customer specific variant, are grouped to the more general constructs of product families (Erens, 1996). While the number of variants in a product family grows over time, the instances that are built of a certain variant declines.

The design work necessary to develop a new product variant can be performed by a product configurator. Configuration in general is defined by Mittal and Frayman (1989) as a design activity with the key feature of the designed artefact being assembled from a predefined set of components that can only be assembled in certain ways. The knowledge of the components and the possible relations between them is assumed to be known at the beginning of a configuration process. Product configurators are tools that support the user during the configuration process or that perform the configuration process automatically.

Configuration tasks (Günter, 1995) are generally classified into routine tasks, innovative tasks, and creative tasks, where the problem and the solution procedure is well defined for routine tasks, while for creative tasks new knowledge needs to be generated to find a solution.

Configuration is today mainly applied to the generation of product variants, especially variants of assembled products. As soon as not the assembly but rather the treatment of one work piece is the predominant subject of planning, the determination of necessary manufacturing steps is rather regarded as a planning problem, more specific a process planning problem, than as a configuration problem.

Process planning is the task of finding relevant processes for manufacturing a product, sequencing these processes and defining the complete set of parameters for each process. Process planning is therefore the task of precisely specifying how to manufacture a particular product.

Computer-aided process planning (CAPP) systems are today used only in a small area of process planning. A 1992 study "raises the assumption that IT-support for NC-programming is more widespread than for process planning. Second, the automation of IT-supported process planning seams to be on a very low level. Planning tasks more difficult than the administration of plans are with few exceptions supported only by specialised process planning systems." (Hamelmann, 1996)

At the same time, the requirements on the process planning increase. The complexity of products to be handled grows through increasing numbers of variants being developed for a certain product family. Customers have enlarged influence not only on the product itself but also on the way this product is manufactured. The amount of knowledge which is used to perform the process planning task grows continuously. This leads to an enlarged effort in maintaining such partially or fully automated planning systems. Nevertheless, the quality of 
automatically produced process plans in terms of resource usage and production cost, just to name two important criteria, is not always sufficient and, in many special cases, needs extensive manual rework.

There are many similarities between product configuration and process planning such as the goals of automation of routine tasks and standardised storing of knowledge or the construction of a structure out of components. As a main difference, the sequence of the components as well as order dependencies of components are aspects that are neglected in product configuration.

It is therefore not farfetched to attempt a transfer of the principles used in product configuration to the structurally similar problem of process planning, which in this context is called process configuration. Single processes form the basic components of the problem. Process and machine knowledge define the conditions under which certain processes are needed and at which position in the plan they are to be placed. Like in product configuration tasks, new types of components (i.e. processes) will not be created during the configuration process.

\section{IMPLEMENTATION OF PROCESS CONFIGURATION}

\subsection{Environment characteristics for the process configuration task}

Based on the features defined in Schönsleben (1998), process configuration seems suited for variant manufacturers producing multiple-variant product families and need variance in their manufacturing processes as well. Still, the process configuration task varies greatly in complexity, from a standard sequence with variable parameters to a fully variable process structure. The requirements on the process configuration vary as much. A morphologic scheme with five features is presented to further detail the possible characterisation of process configuration.

- The process concept defines the manufacturing processes and their sequence using five values Standard processes plans, Standard process sequence with variable parameters, Standard process sequence with variants, General process framework, and Variable process sequence. While standard process plans are similar for every product variant, variation grows in the parameters, the existence of operations in the plan, and in the sequence of these operations.

- Alternative process plans: On a scale ranging from no alternatives to many alternatives, this feature describes how many technically valid alternative process plans exist to manufacture one specific product.

- The complexity of plan generation knowledge characterises the knowledge necessary to create the process plan from the product data.

- The configuration task classification distinguishes between routine configuration, innovative configuration and creative configuration.

- The amount of user influence during the process configuration process is described by the feature degree of automation for plan generation.

Using this morphologic scheme, the following two sub-chapters define and describe two concepts for process configuration, one predominantly manual and 
the other rather automation oriented, and develops the requirements on systems implementing these concepts.

\subsection{Interactive process configuration}

The concept of interactive process configuration aims to define a decision making process for configuration tasks in which user input and system generated data are integrated. Figure 1 shows typical feature values where this concept is applicable:

\begin{tabular}{|c|c|c|c|c|c|}
\hline Feature & \multicolumn{5}{|l|}{ Values } \\
\hline Process concept & $\begin{array}{l}\text { Variable } \\
\text { process } \\
\text { sequence }\end{array}$ & $\begin{array}{l}\text { General } \\
\text { process } \\
\text { framework }\end{array}$ & $\begin{array}{l}\text { Standard } \\
\text { sequence w/ } \\
\text { variants }\end{array}$ & $\begin{array}{l}\text { Standard } \\
\text { sequence w/ } \\
\text { variable } \\
\text { parameters }\end{array}$ & $\begin{array}{l}\text { Standard } \\
\text { processes }\end{array}$ \\
\hline $\begin{array}{l}\text { Alternative } \\
\text { process plans }\end{array}$ & $\begin{array}{l}\text { Many } \\
\text { alternatives }\end{array}$ & & $\begin{array}{l}\text { Some } \\
\text { alternatives }\end{array}$ & $\begin{array}{l}\text { Few } \\
\text { alternatives }\end{array}$ & $\begin{array}{l}\text { No } \\
\text { alternatives }\end{array}$ \\
\hline $\begin{array}{l}\text { Complexity of } \\
\text { plan generation } \\
\text { knowledge }\end{array}$ & $\begin{array}{l}\text { High com- } \\
\text { plexity with } \\
\text { incomplete } \\
\text { knowledge }\end{array}$ & $\begin{array}{l}\text { High } \\
\text { complexity }\end{array}$ & & $\begin{array}{l}\text { Fair } \\
\text { complexity }\end{array}$ & $\begin{array}{l}\text { Simple } \\
\text { complexity }\end{array}$ \\
\hline $\begin{array}{l}\begin{array}{l}\text { Configuration task } \\
\text { classification }\end{array} \\
\end{array}$ & $\begin{array}{l}\text { Creative } \\
\text { configuration }\end{array}$ & & $\begin{array}{l}\text { Innovative } \\
\text { configuration }\end{array}$ & & \begin{tabular}{|l|} 
Routine \\
configuration
\end{tabular} \\
\hline $\begin{array}{l}\text { Degree of automation } \\
\text { for } \\
\text { plan generation }\end{array}$ & Fully manual & $\begin{array}{l}\text { Case-based } \\
\text { with manual } \\
\text { changes }\end{array}$ & $\begin{array}{l}\text { Case-based } \\
\text { or skeleton- } \\
\text { based with } \\
\text { supported } \\
\text { changes }\end{array}$ & $\begin{array}{l}\text { Automated } \\
\text { generation w } \\
\text { possible } \\
\text { interaction }\end{array}$ & $\begin{array}{l}\text { Fully } \\
\text { automated }\end{array}$ \\
\hline
\end{tabular}

Increasing complexity of process configuration task

Figure 1 Features and their values in an interactive process configuration concept

Typical application areas for interactive process configuration are production schemes where the complete knowledge necessary for defining process plans cannot be made available to the planning system. This can be due to reasons such as:

- Lack of structured knowledge: The planning task requires not only technical knowledge but also knowledge about the environment which is not enough structured to be defined in term of rules that can be evaluated by a system. An example for such kind of knowledge is the handling of exceptions.

- Fast changing knowledge: Some areas of the knowledge base are so dynamic that the maintenance of the respective structured knowledge requires an effort much higher than the benefit. This is valid for only rarely used knowledge.

In the cases mentioned above, it is impossible or at least not reasonable to always keep the knowledge base up-to-date and complete. Rather should the incompleteness of the knowledge base be accepted and the system supported process configuration task be designed interactively.

Process configuration patterns that rate even higher on the complexity scale, i.e. that appear further to the left in the morphologic scheme of figure 1, seem only little suited for system supported process configuration. The performed task and 
the used knowledge become so individual that the initial effort for developing a general process framework does not pay off. In that case, a completely manual process planning for each manufactured product is necessary.

Interactive process configuration depends strongly on the communication between the user and the process configuration system. Two aspects are most important for a successful system (Schierholt, 1998):

- A suitable user interface that supports the user is the tasks to be performed and

- A level of communication between user and system that is easy enough to be used intuitively but at the same time expressive enough to describe even complex knowledge structures.

\subsection{Automation-based process configuration}

In contrary to the interactive process configuration concept, which depends strongly on manual interference during the process configuration task, the automation-based process configuration concept assumes an automated process plan generation of most standard product variants but also allows manual interference in cases of exceptions or special orders. Figure 2 shows typical values of features where this concept is applicable:

\begin{tabular}{|c|c|c|c|c|c|}
\hline Feature & Values & & & & \\
\hline Process concept & $\begin{array}{l}\text { Variable } \\
\text { process } \\
\text { sequence }\end{array}$ & $\begin{array}{l}\text { General } \\
\text { process } \\
\text { framework }\end{array}$ & $\begin{array}{l}\text { Standard } \\
\text { sequence w/ } \\
\text { variants }\end{array}$ & $\begin{array}{l}\text { Standard } \\
\text { sequence w/ } \\
\text { variable } \\
\text { parameters }\end{array}$ & $\begin{array}{l}\text { Standard } \\
\text { processes }\end{array}$ \\
\hline $\begin{array}{l}\text { Alternative } \\
\text { process plans }\end{array}$ & $\begin{array}{l}\text { Many } \\
\text { alternatives }\end{array}$ & & $\begin{array}{l}\text { Some } \\
\text { alternatives }\end{array}$ & $\begin{array}{l}\text { Few } \\
\text { alternatives }\end{array}$ & $\begin{array}{l}\text { No } \\
\text { alternatives }\end{array}$ \\
\hline $\begin{array}{l}\text { Complexity of } \\
\text { plan generation } \\
\text { knowledge }\end{array}$ & $\begin{array}{l}\text { High com- } \\
\text { plexity with } \\
\text { incomplete } \\
\text { knowledge } \\
\end{array}$ & $\begin{array}{l}\text { High } \\
\text { complexity }\end{array}$ & & $\begin{array}{l}\text { Fair } \\
\text { complexity }\end{array}$ & $\begin{array}{l}\text { Simple } \\
\text { complexity }\end{array}$ \\
\hline $\begin{array}{l}\text { Configuration task } \\
\text { classification }\end{array}$ & $\begin{array}{l}\text { Creative } \\
\text { configuration }\end{array}$ & & \multirow{2}{*}{$\begin{array}{l}\text { Innovative } \\
\text { configuration } \\
\text { Case-based } \\
\text { or skeleton- } \\
\text { based with } \\
\text { supported } \\
\text { changes }\end{array}$} & & $\begin{array}{l}\text { Routine } \\
\text { configuration }\end{array}$ \\
\hline $\begin{array}{l}\text { Degree of automation } \\
\text { for } \\
\text { plan generation }\end{array}$ & Fully manual & $\begin{array}{l}\text { Case-based } \\
\text { with manual } \\
\text { changes }\end{array}$ & & \multicolumn{2}{|c|}{$\begin{array}{l}\text { Automated Fully } \\
\text { generation w/automated } \\
\text { possible } \\
\text { interaction }\end{array}$} \\
\hline
\end{tabular}

Increasing complexity of process configuration task

Figure 2 Features and their values in an automation-based process configuration concept

The concept of automation-based process configuration can be found in applications where the technical process knowledge can be expressed by rules, constraints and formulas. Process structures within product families show a high degree of similarity. Different requirements are posed on such a system by the different user groups: While in the manufacturing the resulting process plan and its 
expressiveness is of major interest, the planner is looking for an understandable planning process and a high flexibility in using the given tools. The knowledge engineer, who defines the knowledge structure and the planning knowledge, needs an expressive language for knowledge definition. In addition, support for understanding dependencies within the knowledge base is being looked for. The system developer finally is looking for powerful knowledge structuring and reasoning abilities. In summary, the most important needs are strong knowledge description abilities for the knowledge maintenance and flexibility through user influence and interaction as well as ease of use during the planning process.

\subsection{Support of complex process configuration tasks}

A clear and understandable knowledge representation, as f.e. the visually oriented description language described in Schierholt (1998), is not on its own a guarantee for a successful use of the system by the planners. Since the main focus of application is moved from routine to innovative process configuration tasks, the system will in many cases not be able to generate a solution to a given problem automatically. In such cases, the user is to be supported by an application interface allowing him to manipulate the configuration process as well as the resulting solution.

Ideally, for manipulation a language similar to the knowledge definition language is used. Different tasks can be performed using similar looking interfaces. The parameter associated with a given process are displayed during the manipulation phase. The user can now add or delete processes, change process parameters and then recalculate the plan.

A further application of interactivity besides the interactive process configuration shown in section 2.2 is the user-guided optimisation of solutions in a given solution space. Users often have difficulties to define a general optimization function. Giving advice to the system which solution from a given set is closest to the desired one leads the system to look for new solutions with similar characteristics. This can be repeated until an acceptable solution is found.

\section{PROCESS CONFIGURATION IN PRACTICE}

The approaches developed within this research are evaluated in a Swiss metal working company where a process configuration prototype system is being developed. Products of this company are metal sheets. The environment is a typical one for automation-based process configuration. Additionally, the high complexity of plan generation knowledge poses a difficulty on the knowledge representation. The prototype implementation builds on a company-wide ERP-system. This ERPsystem does not provide sufficient CAPP functionality to deal with the desired product spectrum. The prototype implementation consists of two main components, the plan skeleton editor and the process configurator. The plan skeleton editor is designed using the graph-like visualisation ideas that were 
presented in Schierholt (1998). The prototype functionality enables the process planner to define plan skeleton and thus test the expressiveness of the tool.

The process configurator, the application that is actually performing the configuration task, is built using a constrained-based optimisation tool. For each process plan to be configured, it compiles the relevant plan skeleton into a configuration model. The ERP-system supplies the configurator with the product specifications. After finishing the configuration process, the resulting plan is passed back to the ERP-system. The plan can then be visualised and edited using the plan modification editor. The application context is shown in figure 3 .

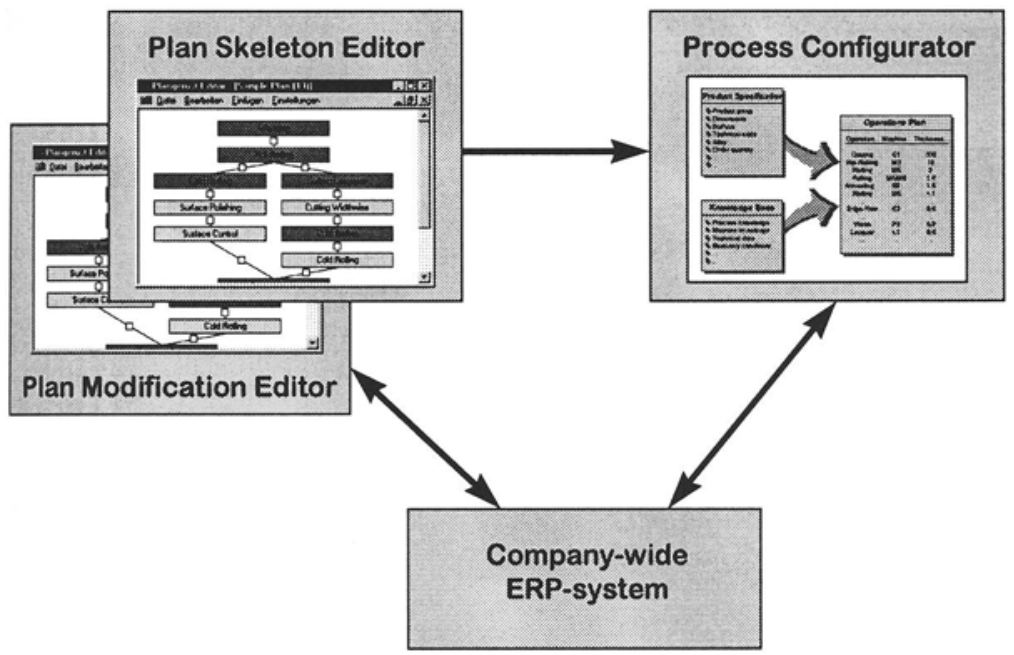

Figure 3 Application overview of the prototype implementation

The prototype system presented in this section is not yet integrated. The single components of the prototype in themselves though generate positive feedback from the users.

\section{CONCLUSION}

Process configuration was presented as a concept for solving the process planning task using principles known from the product configuration concept. Two main concepts for process configuration systems were then presented, the interactive process configuration and the automation-based process configuration. Further explanations were given on how these concepts can be implemented in planning systems. A case study example was given in the end.

Especially the knowledge engineering is regarded as being less complicated with the new approach since many interdependencies between processes are instantly visible. The use of similar interfaces for knowledge maintenance and for the visualisation and manipulation of configured process plans is considered a step forward. 
The prototype system is not yet completed. The system integration in particular is of great importance for the smooth running of the process configuration task. Continued work is also necessary to further check the presented ideas for completeness and to verify them in different application contexts.

\section{ACKNOWLEDGMENTS}

The ProCONFIG-Project (Process Configuration for Multiple-Variant Products: Work Plan Generation for Sheet and Coil Material Production) is the major Swiss input to the IMS-Project GNOSIS - Knowledge Systematization: Configuration Systems for Design and Manufacturing. The project is supported by the Swiss CTI through fund No. KTI 3528.1.

\section{REFERENCES}

Erens, F.J. (1996): The Synthesis of Variety. Diss., Eindhoven Univ. of Techn. Günter, A. (1995): Das Projekt PROKON im Überblick. In Günter, A. (Ed.): Wissensbasiertes Konfigurieren - Ergebnisse aus dem Projekt PROKON. Infix, St. Augustin, Germany, 1995, p. 3-10.

Hamelmann, S. (1996): Systementwicklung zur Automatisierung der Arbeitsplanung. Fortschrittsberichte VDI, Reihe 20, Nr. 195. VDI Verlag, Düsseldorf, Germany, 1996.

Mittal, S. and Frayman, F. (1989): Towards a generic model of configuration tasks. Proceedings of the $11^{\text {th }}$ International Conference on Artificial Intelligence, Detroit, USA, August 1989, p. 1395-1401.

Schierholt, K. (1998): Knowledge Systematization for Operations Plans. Proceedings of the 1998 AAAI Artificial Intelligence and Manufacturing Workshop, Albuquerque, USA, August 1998, p. 140-146.

Schönsleben, P. (1998): Integrales Logistikmanagement - Planung und Steuerung von umfassenden Geschäftsprozessen. Springer, Berlin, Heidelberg, 1998. 